$\S=-1$

\title{
Strength and Durability Characteristics of Steel Fibre Reinforced Geopolymer Concrete
}

\author{
J. Jessy Magdalene Anna ${ }^{1}$, A. Sumathi ${ }^{*}$ \\ ${ }^{1}$ M.Tech in Structural Engineering, ${ }^{2}$ Assistant Professor \\ ${ }^{1,2}$ School of Civil Engineering, SASTRA Deemed University, Thanjavur \\ *Corresponding Author E-mail: ${ }^{2}$ sumathi@ civil.sastra.edu
}

\begin{abstract}
Owing to the upturn inrepair and rehabilitation of structures that undergoes deterioration even before its intended life span; it has become necessary to study the durability properties of the structures. This paper deals with an experimental approach on the strength and durability characteristics of Geopolymer Concrete and Steel Fibre Reinforced Geopolymer Concrete with varying proportions of Fly ash, Waste Glass powder and GGBS (Ground Granulated Blast furnace Slag) as base material cured at room temperature. Sodium hydroxide $(14 \mathrm{M})$ and Sodium silicate are used as alkali activators. Steel fibres of length $60 \mathrm{~mm}, 0.75 \mathrm{~mm}$ diameter are used in two different proportions $(0.25 \%$ and $0.50 \%)$. The results are compared with that of the Portland cement based plain and fibre reinforced control concrete. The durability characteristic involved in this study is Sorptivity test. The results reveal that Steel fibre reinforced Geopolymer concrete procures surpassing characteristics than that of Geopolymer concrete which in turn possess superior characteristics than that of conventional concrete.
\end{abstract}

Keywords: Compressive strength, Sorptivity, Fly ash, Waste glass powder, GGBS, Steel fibres.

\section{Introduction}

The method of manufacturing the Portland cement which is the binding material in conventional concrete releases about 1 tonne of $\mathrm{CO}_{2}$ to the atmosphere for a unit production [1]. Moreover, the conventional concrete structures under particular environmental surroundings are not as much durable [2]. As an alternative, Davidovits [3] set forth the Geopolymer technology. This involves the alkali activation of materials rich in silica and alumina resulting in the formation of inorganic alumina silicate polymers [4]. This approach is environmental friendly and has economical benefits as it involves the usage of industrial by-products [5]. In case of conventional concrete, strengthening is achieved by the hydration of conventional cement and in the case of Geopolymer concrete; the polymerisation process strengthens the structure [6]. The concept of Fibre reinforced concrete has been advanced in the recent years. The incorporation of fibres in the concrete revamps its tensile, flexural and post cracking ductility. Of all, steel fibres are found to increase the tensile and flexural strength, toughness and ductility of concrete significantly. Ganesan et al [7], studied the durability characteristics of plain and fibre reinforced geopolymer concrete and stated that the GPC and SFRGPC specimens attained superior qualities than that of $\mathrm{CC}$ specimens. Faiz Uddin Ahmed Shaikh and Anwar Hosan [8], carried out an investigation experimentally on mechanical properties of fibre reinforced geopolymer concrete with steel fibers at elevated temperatures using $\mathrm{Na}$ and $\mathrm{K}$ based alkaline activators and concluded that both GPC and SFRGPC retained their original mechanical properties upto $400^{\circ} \mathrm{C}$.
The most important phenomenon during the life span of a concrete structure is its durability.

The concrete structures should be capable of withstanding the physical, chemical and mechanical conditions which they are ought to come across during their life period. There are numerous studies being carried out to determine the durability properties of the concrete structures. The durability tests on GPC(Geopolymer Concrete) and SFRGPC (Steel Fibre Reinforced Geopolymer Concrete) such as chloride ion penetrability test, absorption characteristics, resistance to acid attack, resistance to marine attack under alternate wetting and drying conditions have been carried out so far and it has been outlined that they surpass their characteristics when compared to that of $\mathrm{CC}$ (Conventional Concrete) [4], [5], [9], and [10].

Since room cured geopolymer concrete with fly ash shows slow strength development, it has become mandatory to make use of alternatives to make it more suitable for practical applications. Such alternatives include the use of GGBS as a partial replacement of fly ash. Partha Sarathi Deb et al [11] studied the shrinkage and mechanical properties of GPC blended with GGBS and stated that the properties improved with the increase in the percentage of GGBS cured at room temperature. Mostafa Vafaei and Ali Allahverdi [12] carried out an experimental investigation on the feasibility of waste glass powder based GPC along with CAC (Calcium Aluminate Cement) and outlined that it resulted in the significant improvement of material and microstructural properties.

This paper involves the study of strength and durability characteristics of GPC and SFRGPC cured at room temperature. A combination of Fly ash, Waste Glass powder and GGBS at varying proportions is used as base material. The results are then compared with that of plain and fibre reinforced CC. 


\section{Experimental Program}

\subsection{Materials}

Low calcium Class F Fly ash of particle size less than $90 \mu$, Waste Glass Powder of particle size less than $70 \mu$ and GGBS of particle size less than $70 \mu$ were used as the base material of GPC and SFRGPC whereas Ordinary Portland Cement (OPC) 43 grade conforming to IS 8112 (ASTM Type 1) was used as the base material for CC and SFRC. The properties of the base materials are presented in Table 1. The alkaline activator used is a combination of sodium hydroxide and sodium silicate in the ratio of $1: 2$. Sodium hydroxide with $98-99 \%$ purity in the form of flakes was diluted in water to form a solution of $14 \mathrm{M}$ concentration. Sodium silicate solution with the modulus ratio of $\mathrm{SiO}_{2}$ to $\mathrm{Na}_{2} \mathrm{O}$ was $2.61\left(\mathrm{SiO}_{2}=30 \%\right.$ and $\mathrm{Na}_{2} \mathrm{O}=11.5 \%$ and water $=58.5 \%$ ). Steel fibres of $60 \mathrm{~mm}$ length and $0.75 \mathrm{~mm}$ diameter were used in the proportions of $0.25 \%$ and $0.50 \%$. Coarse aggregates of $20 \mathrm{~mm}$ with the specific gravity of 2.73 and locally available river sand of fineness modulus 3.78 and specific gravity 2.71 were used in this investigation. A naphthalene based super plasticizer was added to the mix which improved its workability.

\subsection{Mix design}

M30mix of GPC and CC were designed as per the guidelines given by Rangan [1] and IS 10262-2009 [13] resp. SFRGPC were designed with varying proportions of steel fibres such as $0.25 \%$ $\left(19.32 \mathrm{~kg} / \mathrm{m}^{3}\right)$ and $0.50 \%\left(38.64 \mathrm{~kg} / \mathrm{m}^{3}\right)$. The percentage of GP (Glass Powder) was kept constant at $10 \%$ and the percentage of GGBS varied by $5 \%, 10 \%, 15 \%$ and $20 \%$ for four different mixes. The percentage of fly ash thus varied accordingly. The mix proportions of CC and GPC, SFRC and SFRGPC are listed in Table 2 and Table 3 respectively.

Table 1: Properties of base materials

\begin{tabular}{|c|c|c|c|c|}
\hline \multirow{2}{*}{ Formula } & \multicolumn{4}{|c|}{ Concentration $(\%)$} \\
\hline & Cement & Fly Ash & GP & GGBS \\
\hline $\mathrm{CaO}$ & 69.00 & 1.45 & 8.83 & 45.02 \\
\hline $\mathrm{SiO}_{2}$ & 24.91 & 58.62 & 75.31 & 28.86 \\
\hline $\mathrm{Fe}_{2} \mathrm{O}_{3}$ & 0.20 & 5.28 & - & 0.54 \\
\hline $\mathrm{MgO}$ & 0.04 & 0.65 & 2.80 & - \\
\hline $\mathrm{Na}_{2} \mathrm{O}$ & - & 0.13 & 10.77 & 0.32 \\
\hline $\mathrm{K}_{2} \mathrm{O}$ & - & 1.55 & 0.41 & 0.40 \\
\hline $\mathrm{SO}_{3}$ & - & 0.21 & - & 3.60 \\
\hline $\mathrm{P}_{2} \mathrm{O}_{5}$ & - & 0.58 & - & 0.06 \\
\hline $\mathrm{TiO}_{2}$ & - & 1.80 & - & 0.45 \\
\hline Specific gravity & 3.17 & 2.6 & 2.5 & 2.81 \\
\hline Loss on Ignition & - & 0.70 & 0.32 & 2.37 \\
\hline
\end{tabular}

Table 2: Mix proportions in $\mathrm{kg} / \mathrm{m}^{3}$

\begin{tabular}{|c|c|c|c|c|c|c|c|c|c|c|}
\hline Mix & Cement & Fly ash & GP & GGBS & $\mathrm{NaOH}$ & $\mathrm{Na}_{2} \mathrm{SiO}_{3}$ & $\begin{array}{c}\text { Coarse } \\
\text { Aggregate }\end{array}$ & Fine Aggregate & SP & Water \\
\hline $\mathrm{CC}$ & 380 & - & - & - & - & - & 1160 & 670 & 15 & 171 \\
\hline GPC1 & - & 323 & 38 & 19 & 57 & 114 & 1160 & 670 & 15 & - \\
\hline GPC2 & - & 304 & 38 & 38 & 57 & 114 & 1160 & 670 & 15 & - \\
\hline GPC3 & - & 285 & 38 & 57 & 57 & 114 & 1160 & 670 & 15 & - \\
\hline GPC4 & - & 266 & 38 & 76 & 57 & 114 & 1160 & 670 & 15 & - \\
\hline
\end{tabular}

\subsection{Preparation of Specimens}

Three cubes of $100 \mathrm{~mm} \times 100 \mathrm{~mm} \times 100 \mathrm{~mm}$ and cylinder of $100 \mathrm{~mm} \times 50 \mathrm{~mm}$ were prepared for each mix. The alkaline solutions were prepared 24 hours prior casting. Fine aggregates and the base materials were first mixed uniformly at surface dry conditions. Later coarse aggregates were added and mixed thoroughly.
The alkaline solutions were then added to the mix. For SFRC and SFRGPC mixes, steel fibres were randomly distributed to the mix. After casting, the GPC specimens were kept at room temperature and the $\mathrm{CC}$ specimens were immersed in water for curing.

\begin{tabular}{|c|c|c|c|c|c|c|c|c|c|c|c|}
\hline Mix & $\begin{array}{c}\text { Steel } \\
\text { fibres } \\
(\%)\end{array}$ & Cement & Fly ash & GP & GGBS & $\mathrm{NaOH}$ & $\mathrm{Na}_{2} \mathrm{SiO}_{3}$ & CA & FA & SP & Water \\
\hline SFRC 1-1 & 0.25 & 380 & - & - & - & - & - & 1160 & 670 & 15 & 171 \\
\hline SFRC 1-2 & 0.50 & 380 & - & - & - & - & - & 1160 & 670 & 15 & 171 \\
\hline SFRGPC 1-1 & 0.25 & - & 323 & 38 & 19 & 57 & 114 & 1160 & 670 & 15 & - \\
\hline SFRGPC 1-2 & 0.50 & - & 323 & 38 & 19 & 57 & 114 & 1160 & 670 & 15 & - \\
\hline SFRGPC 2-1 & 0.25 & - & 304 & 38 & 38 & 57 & 114 & 1160 & 670 & 15 & - \\
\hline SFRGPC $2-2$ & 0.50 & - & 304 & 38 & 38 & 57 & 114 & 1160 & 670 & 15 & - \\
\hline SFRGPC 3-1 & 0.25 & - & 285 & 38 & 57 & 57 & 114 & 1160 & 670 & 15 & - \\
\hline SFRGPC 3-2 & 0.50 & - & 285 & 38 & 57 & 57 & 114 & 1160 & 670 & 15 & - \\
\hline SFRGPC 4-1 & 0.25 & - & 266 & 38 & 76 & 57 & 114 & 1160 & 670 & 15 & - \\
\hline SFRGPC 4-2 & 0.50 & - & 266 & 38 & 76 & 57 & 114 & 1160 & 670 & 15 & - \\
\hline
\end{tabular}

\section{Results and Discussion}

\subsection{Compressive Strength Test}

It is the most common test carried out to determine the structural properties of concrete. For this test, cubes of size
$100 \mathrm{mmx} 100 \mathrm{mmx} 100 \mathrm{~mm}$ were cast and cured at room temperature before being tested. The test was done in a CTM of $3000 \mathrm{kN}$ capacity after 28 and 56 days of curing as per IS 516: 1959 under normal room temperature. The results are shown in Table 4.

The compressive strength of the mixes GPC 1 and GPC 2 was found to be lesser than that of CC. 
This is because of the less percentage of GGBS in the mix. Whereas, the higher compressive strength of GPC 3 and GPC 4 denotes that increase in addition of GGBS $(\geq 15 \%)$ increased the strength abruptly. With the addition of fibres SFRC1-1 and SFRC 1-2 showed better results than CC.

Like in the previous case, mixes with $<15 \%$ GGBS namely SFRGPC 1-1, SFRGPC 1-2, SFRGPC 2-1 and SFRGPC 2-2 showed lesser compressive strength than SFRC 1-1 and SFRC 1-
2. However, SFRGPC 3-1, SFRGPC 3-2, SFRGPC 4-1 and SFRGPC 4-2 showed significant increase in compressive strength when compared with the other mixes. This may be due to the fact that the fibres fill the voids in concrete thereby increasing its strength. Maximum average compressive strength of $47.27 \mathrm{MPa}$ was achieved for SFRGPC 4-2 at 56 days.

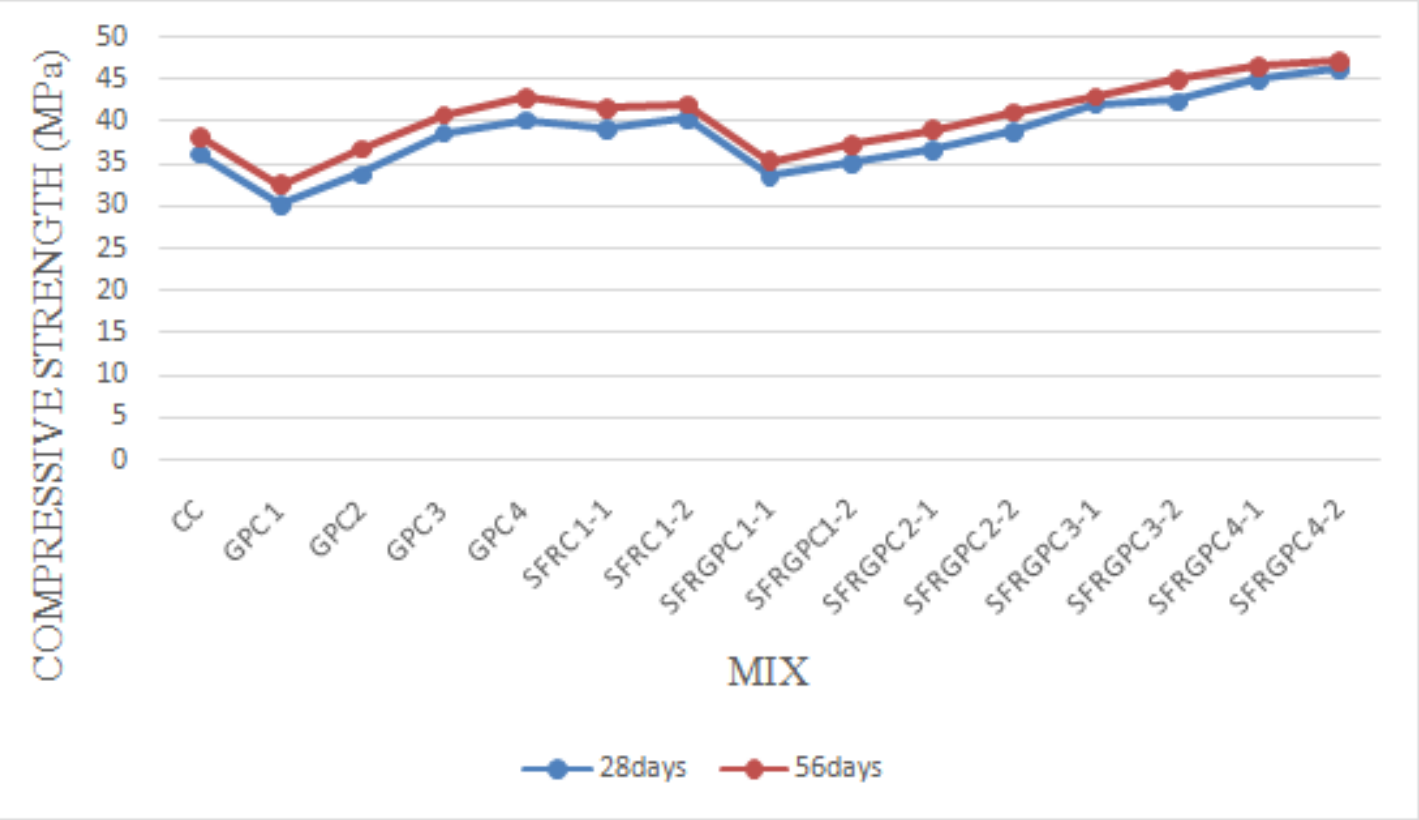

Fig. 1: Compressive strength test results

Table 4: Compressive strength test results

\begin{tabular}{|c|c|c|}
\multicolumn{2}{c}{ Table 4: Compressive strength test results } \\
\cline { 2 - 3 } Mix & \multicolumn{2}{|c|}{ Compressive strength, MPa } \\
\hline CC & 28 days & 56 days \\
\hline GPC 1 & 36.23 & 38.12 \\
\hline GPC 2 & 30.21 & 32.43 \\
\hline GPC 3 & 33.8 & 35.67 \\
\hline GPC 4 & 38.7 & 40.72 \\
\hline SFRC 1-1 & 40.23 & 42.78 \\
\hline SFRC 1-2 & 39.2 & 41.53 \\
\hline SFRGPC 1-1 & 40.32 & 41.95 \\
\hline SFRGPC 1-2 & 33.62 & 35.33 \\
\hline SFRGPC 2-1 & 35.13 & 37.24 \\
\hline SFRGPC 2-2 & 36.77 & 39.02 \\
\hline SFRGPC 3-1 & 38.8 & 41.05 \\
\hline SFRGPC 3-2 & 41.09 & 42.88 \\
\hline SFRGPC 4-1 & 42.46 & 41.96 \\
\hline SFRGPC 4-2 & 45.08 & 46.53 \\
\hline
\end{tabular}

\subsection{Sorptivity Test}

The test based on Darcy's law of unsaturated flow determines the ability of concrete to absorb water by capillary action. Here, cylinders of size $100 \mathrm{mmx} 50 \mathrm{~mm}$ were cast and after its curing period, the specimens were kept in oven at $50 \pm 2^{0} \mathrm{C}$ for 24 hours. The specimens were then removed and cooled at room temperature before being tested. The specimens were immersed in water to a depth of 5 to $10 \mathrm{~mm}$ from the bottom with all the three sides sealed using a plastic tape. The initial dry weight of the sample was taken as $\mathrm{W}$. The gain in weight of the specimens at 30 mins, 60mins, 90mins and 120 mins after being immersed in water were taken.

The results show that the rate of absorption is less in GPC and SFRGPC when compared to CC and SFRC mixes.This may be due to better microstructural properties of GPC and SFRGPC. Adiition of fibres in less proportion decreased the sorptivity of both CC and GPC thus making it more durable. The fibres fill the voids of concrete as the concrete flows through the fibres and making the concrete denser. Thus, less amount of water penetrates through these mixes and provide better microstructural properties. 


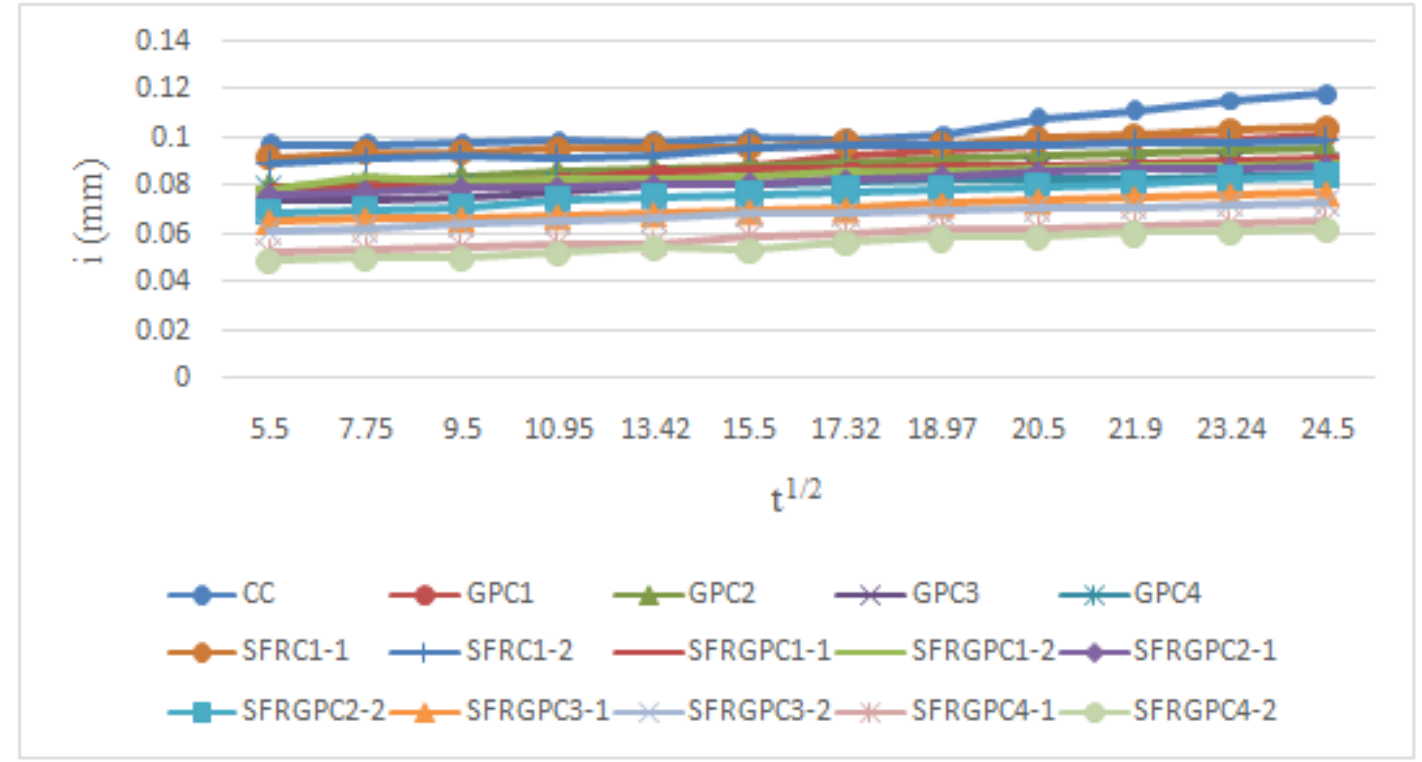

Fig. 2: Sorptivity Test Results

\section{Conclusions}

In this study, GPC and SFRGPC specimens were prepared using different proportions of Fly ash, GP and GGBS. The alkaline solutions used were $\mathrm{NaOH}(14 \mathrm{M})$ and $\mathrm{Na}_{2} \mathrm{Si}_{2} \mathrm{O}_{3}$. The specimens were cured at room temperature for 28 and 56 days and tested for compressive strength and sorptivity. From the results obtained, the following conclusions were made:

1. The M30mixes of GPC and SFRGPC were compared with that of CC and SFRC. It was seen that with the addition of GGBS increased the strength and decreased the period of binding at room temperature. The binding period for GPC1 and GPC2 took nearly 3days while for GPC3 and GPC4 the binding period was decreased to 24 hours.

2. The compressive strength test results show that SFRGPC and GPC have better strength than SFRC and CC respectively.

3. The sorptivity tests reveal that curve for GPC and SFRGPC were less linear when compared to CC and SFRC.

It can be concluded that GPC and SFRGPC has very low rate of absorption than CC and SFRC. The addition of fibers further lowered the rate of absorption.

\section{References}

[1] Rangan BV 2006, "Studies on low calcium fly ash based geopolymer concrete", Indian Concr J 9-17.

[2] Neville AM 1995,"Properties of concrete", 4th ed. New York: John Wiley \& Sons.

[3] Davidovits J 1994,"High alkali cements for 21st century concretes in concrete technology - past, present and future", Proceedings of V. Mohan Malhotra symposium, ACI SP 144 383-397.

[4] Bakharev T 2005,"Resistance of geopolymer materials to acid attack", Cem Concr Res 35(4) 658-70.

[5] Bakhrev T.2005, "Durability of geopolymer materials in sodium and magnesium sulphate solutions", Cem Concr Res 35 1233-46.

[6] Frantisek S, Lubomir K, Jiri N, Zdenek B 2006,"Microstructure of geopolymer materials based on fly ash", Ceram-Silik 50 208-15.

[7] Ganesan N, Ruby Abraham, Deepa Raj S 2015,"Durability characteristics of steel fibre reinforced geopolymer concrete",Construction and Building Materials 93 471-476.

[8] Faiz Uddin, Ahmed Shaikh and Anwar Hosan 2017,"Mechanical properties of steel fibre reinforced geopolymer concretes at elevated temperatures",Construction and Building Materials, 11415 - 28.

[9] Rajamane NP, Nataraja MC, Lakshmanan N, Dattatreya JK 2011,"Rapid chloride permeability test on geopolymer and Portland cement",Indian Concr J 21-6.
[10] Sathia R, Ganesh Babu, Manu Santhanam 2008,"Durability study of low calcium fly ash geopolymer concrete", The 3rd ACF international conference, 1153-1159.

[11] Partha Sarathi Deb, Pradip Nath, Prabir Kumar Sarker 2015, "Drying shrinkage of slag blended fly ash geopolymer concrete cured at room temperature", Procedia Engineering 125 $594-600$.

[12] Mostafa Vafaei , Ali Allahverdi 2017,"High strength geopolymer binder based on waste-glass powder", Advanced Powder Technology, 28 215-222.

[13] IS: 10262 standard code of practice for recommended guidelines for concrete mix design. New Delhi: BIS. 